\title{
Chapter 7 \\ Causes of Death at Very Old Ages, Including for Supercentenarians
}

\author{
France Meslé and Jacques Vallin
}

The causes of death reported on the death certificates of the oldest old are generally seen as unreliable, and as thus providing little useful information on the process leading to death (Mathers et al. 2005). However, in advanced countries, a majority of the people who die each year are older and older. In France, for example, the share of all female deaths that occurred among the 85+ age group was $73 \%$ in 2016 , up from $62 \%$ in $2000,41 \%$ in 1975 , and just $25 \%$ in 1950 ; and the proportion of all female deaths that occurred among the $90+$ age group was $45 \%$ in 2016, up from $32 \%$ in $2000,15 \%$ in 1975 , and less than $7 \%$ in $1950 .{ }^{1}$ For several decades, researchers have been calling for further investigation into the causes of death at old ages (Meslé 2006), and for efforts to identify groups of causes that characterize the oldest old population (Berzlanovich et al. 2005; Horiuchi 2006; Motta et al. 2010; Evans et al. 2014). Indeed, in many countries, increasingly detailed information on causes of death is being provided on medical certificates. At the same time, scholars are becoming more interested in studying not just the initial cause of death, but multiple causes of death, thereby taking all of the information reported on the certificate into account (Nam et al. 1994; Désesquelles et al. 2014a).

Looking at the case of France, it appears that additional information can now be derived from a precise examination of medical death records. In our analysis, we will seek to determine the initial causes of death by single year of age among individuals who died between the ages of 90 and 117 during the 2000-2014 period. ${ }^{2}$ After briefly presenting the available data, we will investigate how the underlying

\footnotetext{
${ }^{1}$ To allow for a proper comparison, these proportions are computed on the basis of the life table deaths.

${ }^{2}$ For metropolitan France only; and thus excluding overseas territories (Départements d'OutreMer, Territoires d'Outre-Mer, and others) that account for about $2 \%$ of the total population.
}

F. Meslé $(\bowtie) \cdot J$. Vallin

Institut national d'études démographiques (INED), Paris, France

e-mail: mesle@ined.fr; vallin@ined.fr 
cause-of-death structure changed over the study period. We will then focus on deaths among supercentenarians (aged 110 or older). For these still rather exceptional cases, it is essential that we take benefit of all the information available on the death certificate (the so-called "multiple causes"), to attempt to identify the reasons why a particular underlying cause was chosen. Indeed, multiple causes are more and more considered in the literature as an important clue for understanding the full process of events leading to death even at very old age (Désesquelles et al. 2014b).

\subsection{Available Data}

The only source of data on causes of death in France is INSERM ${ }^{3}$, the French Institute for Health and Medical Research. Since 1968, INSERM has been responsible for producing these cause-of-death statistics, having taken over this task from $\mathrm{INSEE}^{4}$, the French National Institute for Statistics and Economic Surveys. For several decades, INSERM was simply coding the causes of death and passing this information on to INSEE, which performed the necessary computations and provided INSERM with the results that they then published. During this period, the data on total deaths by sex, age, and other demographic characteristics published by INSEE and the cause-of-death data published by INSERM were perfectly aligned. Unfortunately, this situation changed in 1998, when INSERM started producing results independently of INSEE. The total numbers published in the vital statistics (produced by INSEE) and the cause-of-death counts started to diverge. Fortunately, as the discrepancy between these figures is very small (less than $0.2 \%$ up to age 108), it should not affect the results of our study (Table 7.1).

However, the statistics for France published by both INSERM and INSEE continue to suffer from some degree of age inaccuracy at very old ages. This is the case in all countries, including those that maintain the most accurate vital statistics. Within the framework of an international group conducting research on supercentenarians (people aged 110 or older), great efforts were made to check the ages at death of the oldest old by matching their death and birth certificates (Maier et al. 2010). The results of this work are available in the International Database on Longevity (IDL) (Cournil et al. 2010). Thus, all deaths at ages 110 or older that occurred in France up to 2014 have been checked (Meslé et al. 2010). For our study on causes of death among the oldest old, we have chosen to use data starting in 2000, the year when the 10th revision of the International Classification of Diseases (ICD-10) was implemented, in order to avoid statistical disruptions resulting from classification changes. It is essential that we take into account the transition from the use of ICD-9 to the use of ICD-10, not only because the international classification changed, but also because when INSERM adopted ICD-10 it also adopted an

\footnotetext{
${ }^{3}$ Institut national de la santé et de la recherche médicale.

${ }^{4}$ Institut national de la statistique et des enquêtes économiques.
} 
Table 7.1 Total numbers of deaths 2000-2014, by sex, age, and source (Metropolitan France only, excluding overseas territories)

\begin{tabular}{|c|c|c|c|c|c|c|}
\hline & \multicolumn{3}{|l|}{ Males } & \multicolumn{3}{|l|}{ Females } \\
\hline & INSEE & INSERM & $\begin{array}{l}\text { Relative } \\
\text { difference } \\
(\%)\end{array}$ & INSEE & INSERM & $\begin{array}{l}\text { Relative } \\
\text { difference (\%) }\end{array}$ \\
\hline 90 & 87,942 & 88,012 & -0.1 & 163,663 & 163,830 & -0.1 \\
\hline 91 & 76,592 & 76,607 & 0.0 & 156,941 & 157,046 & -0.1 \\
\hline 92 & 64,023 & 64,016 & 0.0 & 145,320 & 145,463 & -0.1 \\
\hline 93 & 52,189 & 52,143 & 0.1 & 130,402 & 130,466 & 0.0 \\
\hline 94 & 40,912 & 40,884 & 0.1 & 112,514 & 112,602 & -0.1 \\
\hline 95 & 31,550 & 31,522 & 0.1 & 96,026 & 96,129 & -0.1 \\
\hline 96 & 24,038 & 24,009 & 0.1 & 82,126 & 82,191 & -0.1 \\
\hline 97 & 18,146 & 18,137 & 0.0 & 67,470 & 67,549 & -0.1 \\
\hline 98 & 13,088 & 13,085 & 0.0 & 53,964 & 54,051 & -0.2 \\
\hline 99 & 8890 & 8879 & 0.1 & 41,190 & 41,221 & -0.1 \\
\hline 100 & 5744 & 5726 & 0.3 & 29,677 & 29,709 & -0.1 \\
\hline 101 & 3487 & 3474 & 0.4 & 20,493 & 20,533 & -0.2 \\
\hline 102 & 2047 & 2045 & 0.1 & 13,258 & 13,266 & -0.1 \\
\hline 103 & 1134 & 1131 & 0.3 & 8268 & 8272 & 0.0 \\
\hline 104 & 585 & 580 & 0.9 & 4829 & 4828 & 0.0 \\
\hline 105 & 310 & 307 & 1.0 & 2853 & 2852 & 0.0 \\
\hline 106 & 151 & 153 & -1.3 & 1543 & 1540 & 0.2 \\
\hline 107 & 57 & 53 & 7.0 & 806 & 807 & -0.1 \\
\hline 108 & 47 & 47 & 0.0 & 403 & 404 & -0.2 \\
\hline 109 & 20 & 18 & 10.0 & 180 & 178 & 1.1 \\
\hline 110 & 6 & 6 & 0.0 & 75 & 75 & 0.0 \\
\hline 111 & 3 & 3 & 0.0 & 41 & 42 & -2.4 \\
\hline 112 & 1 & 1 & 0.0 & 17 & 17 & 0.0 \\
\hline 113 & 0 & 0 & & 5 & 6 & -20.0 \\
\hline 114 & 0 & 0 & & 5 & 4 & 20.0 \\
\hline 115 & 0 & 0 & & 1 & 1 & 0.0 \\
\hline 116 & 1 & 1 & 0.0 & 1 & 0 & 100.0 \\
\hline 117 & 1 & 1 & 0.0 & 2 & 2 & 0.0 \\
\hline 118 & 0 & 0 & & 0 & 0 & \\
\hline 119 & 0 & 0 & & 1 & 0 & 100.0 \\
\hline 120 & 0 & 0 & & 0 & 0 & \\
\hline Total & 430,964 & 430,840 & 0.0 & $1,132,074$ & $1,133,084$ & -0.1 \\
\hline
\end{tabular}

Source: Civil registration (INSEE); CépiDc (INSERM)

automated approach to coding causes of death. For our comparison of multiple causes with underlying causes of death, we believe that this change may have been even more consequential than the classification revision. The period under study (2000-2014) is also the period when the numbers of deaths at the oldest ages became large enough to be analysed. 


\subsection{An Overview of Causes of Death at Old Age in 2000-2014}

Figure 7.1 shows how the distribution of deaths by nine large groups of causes changed with age at ages $90+$ (Table 7.2).

Deaths are displayed by year of age up to the highest age attained (here, the highest age for both sexes is 117). However, it would be wrong to pay too much attention to the ages above 112. As we explain in more detail in section III, the numbers of deaths at ages 112+ were not only very small, they may contain errors because the ages listed in the INSERM data were not checked for accuracy. The most important here is to see how much the proportion of ill-defined or unspecified causes grows with age regularly. It rises from a bit less than $10 \%$ at age 90 to more than $40 \%$ after age 110 .

Nevertheless, it is also very interesting to note that an underlying cause of death was identifiable even up to very old ages: i.e., for more than $65 \%$ of deaths up to ages 105-110, and for more than 55\% of deaths at age 111. Another important finding is that the proportions of deaths from heart diseases, other circulatory diseases, and infectious and respiratory diseases were relatively stable across the age groups: i.e., at around 25\%,10\%, and 10\%, respectively. By contrast, the proportions of deaths from neoplasms, diabetes, and dementia/Alzheimer's were decreasing with age.

Figure 7.2 shows that no large differences can be observed between men and women, except that because of a number of deaths much lower among males than among females at these very old ages the graph becomes erratic at an earlier stage

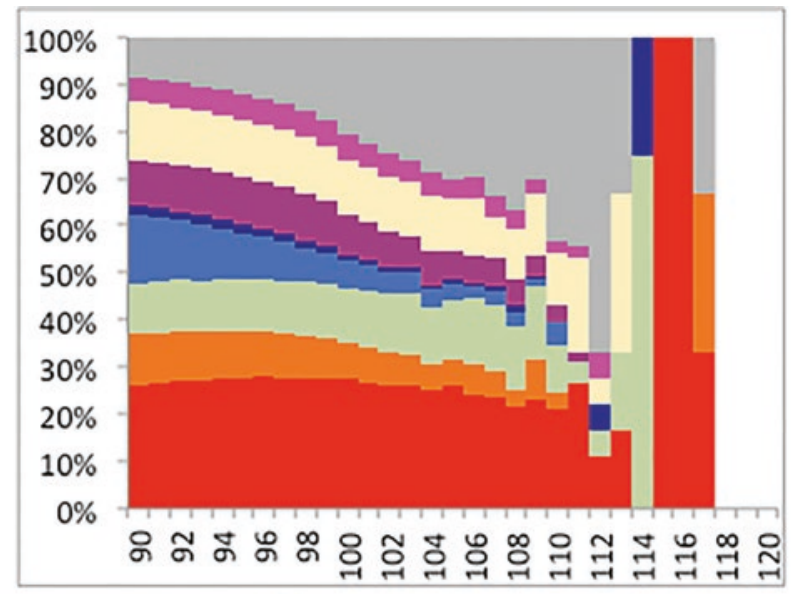

\begin{tabular}{|c|c|c|}
\hline IIII defined and unknown & External causes & Other diseases \\
\hline Dementia + Alz & Diabetes & Neoplasms \\
\hline Inf. + resp. dis. & Other circ. dis. & neart diseas \\
\hline
\end{tabular}

Fig. 7.1 Age-specific proportions (\%) of deaths by group of causes (2000-2014): both sexes. (Source: files provided by CépiDc) 
Table 7.2 Correspondence in ICD-10 of the groups and sub-groups of causes used

\begin{tabular}{|c|c|c|}
\hline Group & Causes & $\begin{array}{l}\text { ICD-10 } \\
\text { code }\end{array}$ \\
\hline \multirow[t]{6}{*}{1} & Heart diseases & I00-I528 \\
\hline & \multirow[t]{3}{*}{ Specified heart diseases } & $100-1459$ \\
\hline & & I470-1499 \\
\hline & & I510-I528 \\
\hline & \multirow{2}{*}{ Cardiac arrest, heart failure } & I460-I469 \\
\hline & & $1500-1509$ \\
\hline 2 & Other circulatory diseases & I600-I99 \\
\hline \multirow[t]{2}{*}{3} & \multirow[t]{2}{*}{ Infectious and respiratory diseases } & A000-B99 \\
\hline & & J00-J998 \\
\hline 4 & Neoplasms & C000-D489 \\
\hline 5 & Diabetes & E10-E149 \\
\hline \multirow[t]{6}{*}{6} & \multirow[t]{3}{*}{ Neuro-degenerative diseases } & F000-F039 \\
\hline & & G20-G269 \\
\hline & & G300-G319 \\
\hline & \multirow{2}{*}{$\begin{array}{l}\text { Parkinson's disease, other extrapyramidal disorders, and Alzheimer's } \\
\text { disease }\end{array}$} & $G 20-G 269$ \\
\hline & & G300-G319 \\
\hline & Vascular and unspecified dementia & F000-F039 \\
\hline \multirow[t]{6}{*}{7} & \multirow[t]{6}{*}{ Other diseases } & B500-E079 \\
\hline & & E15-E90 \\
\hline & & F04-G149 \\
\hline & & G320-G457 \\
\hline & & G460-H959 \\
\hline & & K000-Q999 \\
\hline 8 & External causes & V010-Y98 \\
\hline \multirow[t]{5}{*}{9} & Ill-defined and unknown causes & R000-R99 \\
\hline & Senility & $R 54$ \\
\hline & \multirow[t]{2}{*}{ Other ill-defined cause } & R000-R539 \\
\hline & & $R 55-R 989$ \\
\hline & Unknown cause & $R 99$ \\
\hline
\end{tabular}

among males than among females. It is also worth noting that while the share of deaths from cancer diminishes rapidly with age among both sexes, this share is much more pronounced among males than among females at age 90. Conversely, we find that infectious and respiratory diseases increase with age among males, but less so among females.

Indications that ill-defined information increases with age was not limited to the category of "ill-defined and unknown causes". In each large group of specified causes, it is known that some items are less precise than others. For these less specified causes, we also observe that the proportions increase with age. We see this pattern when, for example, we compare "specified heart diseases" with "cardiac arrest and heart failure" (Fig. 7.3), or "Alzheimer's disease" with "vascular and other dementias" (Fig. 7.4). However, in these cases as well we observe that the 
MALES

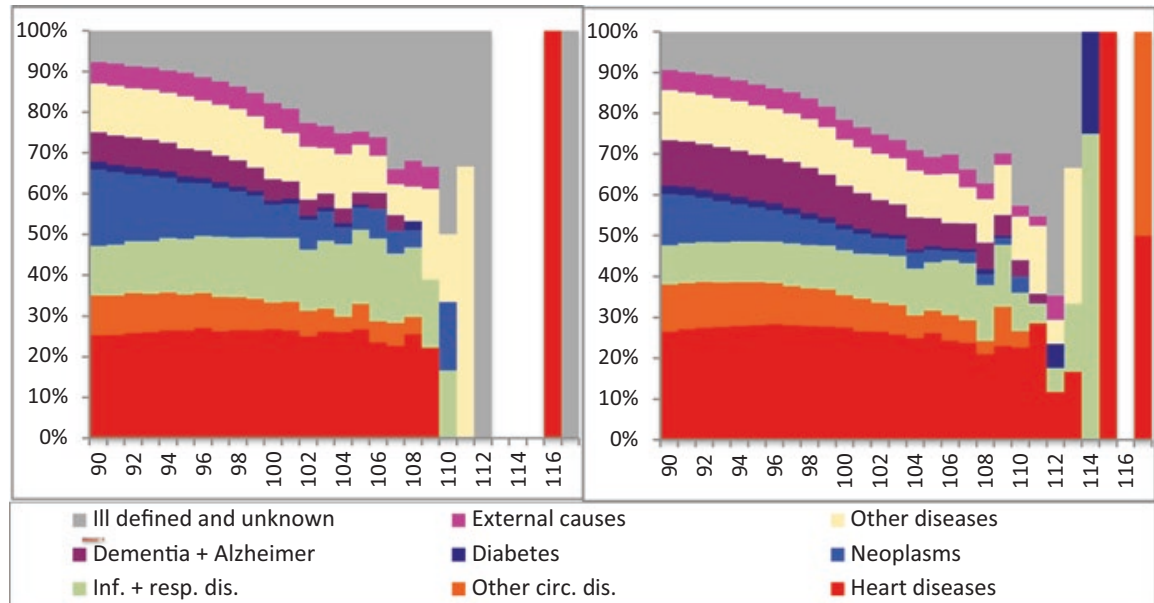

Fig. 7.2 Age-specific proportions (\%) of deaths by sex and group of causes (2000-2014). (Source: files provided by CépiDc)

MALES

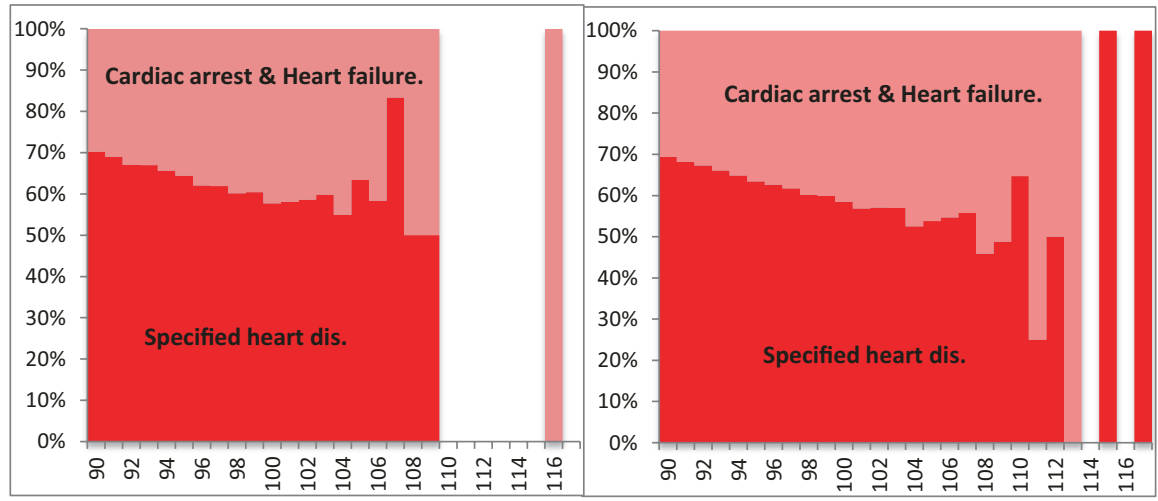

Fig. 7.3 Age-specific proportions (\%) of deaths by group within heart diseases (2000-2014). (Source: files provided by CépiDc)

proportions of the most precise causes were never negligible. These results clearly suggest that exploring causes of death is worthwhile, even at very old ages.

Furthermore, if we join these unspecified sub-categories to the group of "illdefined causes" (Fig. 7.5), we can see that although the total number of deaths in these categories increase considerably with age, the proportion of deaths from "specified diseases" remains important through the end of the significant data: among males, the proportion changes from $80 \%$ at age 90 to $50 \%$ at age 110 ; and among females, the decrease is even smaller, from $78 \%$ at age 90 to $53 \%$ at age 110 .

It is also interesting to look at the distribution of the sub-categories of ill-defined causes: "senility", "other ill-defined causes", and "unknown cause" (Fig. 7.6). 
MALES

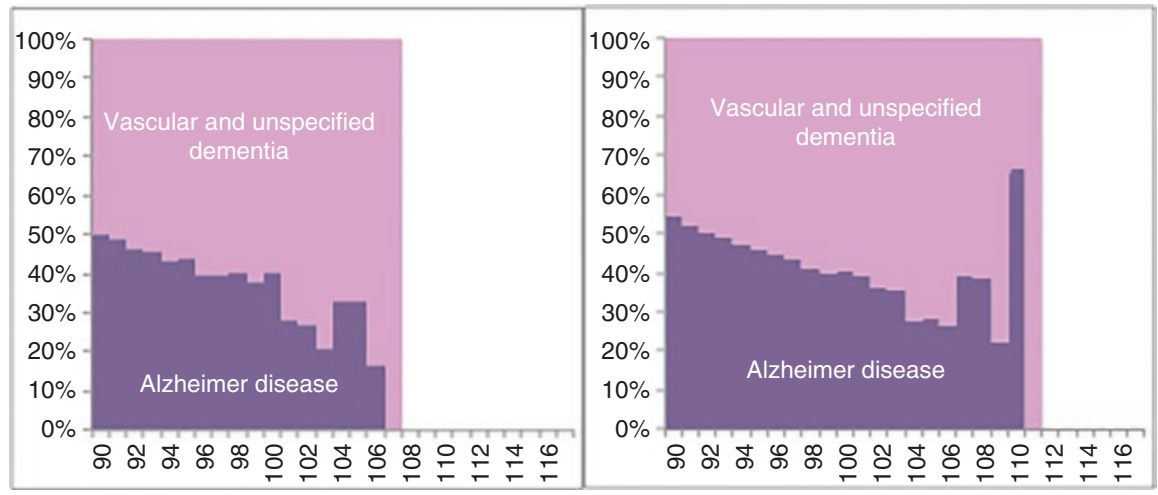

Fig. 7.4 Age-specific proportions (\%) of deaths by group within dementias (2000-2014). (Source: files provided by CépiDc)

MALES

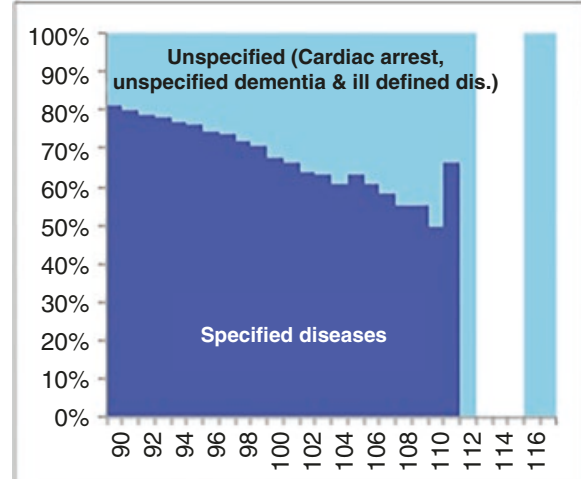

Fig. 7.5 Age-specific proportions (\%) of deaths by specified vs unspecified causes (2000-2014). (Source: files provided by CépiDc)

While "other unspecified causes of death" decrease rapidly, "unknown cause" does not increase (it even decreases until around age 100). By contrast, "senility" increases. In this context, the question of whether "senility" can be seen as a real cause of death arises. We explore this issue further in the next section.

\subsection{Supercentenarian Deaths by Cause Using Multiple Causes}

While the statistics for deaths at very old ages cannot be considered fully reliable, we can look at individual cases to investigate whether the selected underlying cause is an accurate summary of all of the information reported on the cause-of-death certificate (Désesquelles et al. 2014a). For each death, we obtained from INSERM the complete 
MALES

FEMALES

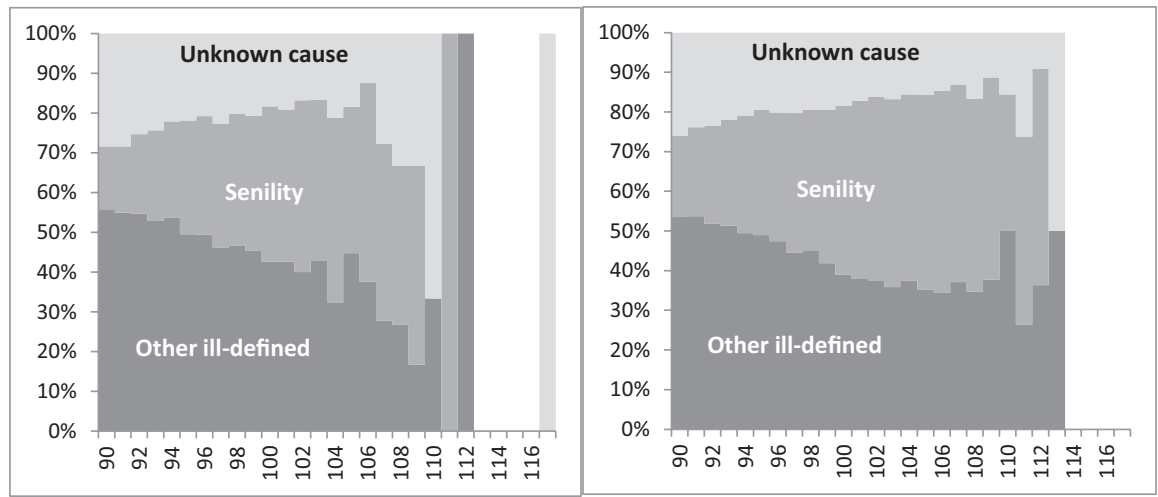

Fig. 7.6 Age-specific proportions (\%) of deaths by group within ill-defined causes (2000-2014). (Source: files provided by CépiDc)

list of all of the original information written on the certificate by the medical doctor who reported the death, in its original wording. The form the doctor completed has two parts. In part I, each step of the lethal process has to be reported, from the most immediate cause to the initial one (several lines are provided for this information). In part II, the medical doctor can report any other condition or health event that may have contributed to the death, but did not cause it directly (associated causes).

Thus, for each case, the multiple causes can be compared to the selected underlying cause. It was our view that making such a comparison for all deaths of supercentenarians (aged 110+) would be quite informative. However, to ensure accurate results, we had to consider that even now, the reported ages in such exceptional cases must be proven. To ensure that we were dealing with true supercentenarians, we used the French part of the International Database on Longevity (IDL) to check the exact ages at death of the individuals listed in the INSERM file as supercentenarians. Out of a total of 160 cases of death at age 110+ listed in the INSERM file, 115 cases were validated ${ }^{5}$, while the remaining 45 cases were not validated (either because the age was wrong or because matching the death with the birth certificate was impossible for various reasons).

After comparing the underlying and the multiple causes of death for each of these 115 true supercentenarians, we distinguished four possible degrees of knowledge about the cause of a supercentenarian death:

(A) a specific disease that caused the death was reported;

(B) a specific disease was reported, but the individual was in poor overall physical condition;

\footnotetext{
${ }^{5}$ In the framework of the international research group on supercentenarians, strict rules for age validation have been established. In particular, it is recommended that the death certificate be matched with an early piece of personal identification, which should ideally be the birth certificate. In France, the validation was strictly based on matching the death with the birth certificate. This process of validation was systematically done for all reported supercentenarians (aged $110+$ ).
} 
(C) the individual's physical condition had deteriorated, but no precise cause of death was identified; or

(D) the individual was reported to have died of natural causes or old age.

In the following, we discuss some specific examples. For all these examples, a small frame gives:

- the sex and age of the deceased;

- the ICD-10 code of the underlying cause chosen and its title (in bold);

- all of the information written in French by the physician in part I of the certificate (in italics), and the translation of this information into English (in upright);

- and, if any, the information written in French by the physician in part II of the certificate (in italics) and the translation of this information into English (in upright).

\section{(A) Examples in which "a specific disease caused the death"}

In Example 1, the underlying cause of death of a woman aged 113 is coded as an "ulcer of oesophagus", item K221 of the ICD-10. No precise information about the woman's condition is provided. The additional notes made by the medical doctor in part I of the certificate describe a logical progression from the appearance of a peptic ulcer of the oesophagus to the development of a digestive haemorrhage. The underlying cause that was reported (in bold here below) appears to be correct, and it is clear that this woman's death was attributable to a well-specified cause, without any mention of any symptom of an overall deterioration in her health.

\section{Example 1. Woman, Aged 113: K221: Ulcer of Oesophagus}

Information given on part I of the certificate:

- hémorragie digestive [digestive haemorrhage]

- antécédents ulcère gastrique [history of gastric ulcer]

- ulcère peptique oesophagien [peptic ulcer of the oesophagus]

Similarly, in Example 2, which refers to the death of a woman at age 110, the underlying cause was identified as "acute myocardial infarction, unspecified" (code I219 in ICD-10). This can be seen as a precise cause, even though the AMI is unspecified. The information provided on the certificate leaves no doubt about the underlying cause.

\section{Example 2. Woman, Aged 110: I219: Acute Myocardial}

Infarction (AMI), Unspecified

Information given on part I of the certificate:

- ischémie aiguë [acute ischaemia]

- embolie [embolism]

- TACFA [tachyarrhythmia with atrial fibrillation] 
(B) Examples of "a specific disease or injury with worsening overall physical health"

In Example 3, the death of a woman aged 111 was attributed to "exposure to unspecified factor causing other and unspecified injury" (code X599, ICD-10). If the case were that of a younger adult, choosing this cause of death might have made sense. But because the case was that of a 111-year-old woman, selecting this cause may not have been appropriate, as her age and general physical deterioration could have been the cause of the fall itself. Even if the underlying cause chosen is correct according to the ICD rules of coding, it is clear that such rules are less pertinent at older than at younger ages. It is important to consider here that the worsening of the woman's overall physical condition likely played a non-negligible role in her death.

\section{Example 3. Woman, Aged 111: X599: Exposure to Unspecified Factor} Causing Other and Unspecified Injury

Information given on part I of the certificate:

- arrêt cardio-respiratoire [cardiorespiratory arrest]

- altération état général [general physical deterioration]

- grabataire [bedridden]

- fracture du col du fémur [fracture of neck of femur]

- accident [accident]

In Example 4 (a man aged 110), the choice of "malignant neoplasm of prostate" (code C61, ICD-10) as the underlying cause of death is even more striking. It is stipulated in the ICD rules that when only vague causes are mentioned in part I but if a precise cause is reported in part II, the precise cause should be chosen as the underlying cause of death. However, in the case of this 110-year-old man, it is unclear whether his prostate cancer was more responsible for his death than simply "old age". If his cancer had been sufficiently advanced to have caused his death, it is likely that the medical doctor would have mentioned the cancer in part I. For that reason, we put this case in category B.

\section{Example 4. Man, Aged 110: C61: Malignant Neoplasm of Prostate}

Information given on part I of the certificate:

- défaillance cardio-respiratoire [cardiorespiratory failure]

- grand âge [old age]

Information given on part II of the certificate

- cancer de la prostate [cancer of prostate] 


\section{(C) Examples of "the worsening of the individual's overall physical condi- tion, without a specific disease"}

The third category brings together cases in which the worsening of the person's overall physical condition is the only known cause of death. In Example 5, the death of a woman aged 111 was attributed to "unspecified protein-energy malnutrition" (code E46, ICD-10), which could appear to be a precise cause. But all of the other information provided suggests that malnutrition was not the initial cause. It is clear that severe failures or disorders of the woman's fundamental functions were mainly responsible for her death. The "senescence" reported on the last line of part I might have also been selected. The most concise summary of the information provided is that the woman experienced a general deterioration in her health, and not a precise nutritional process.

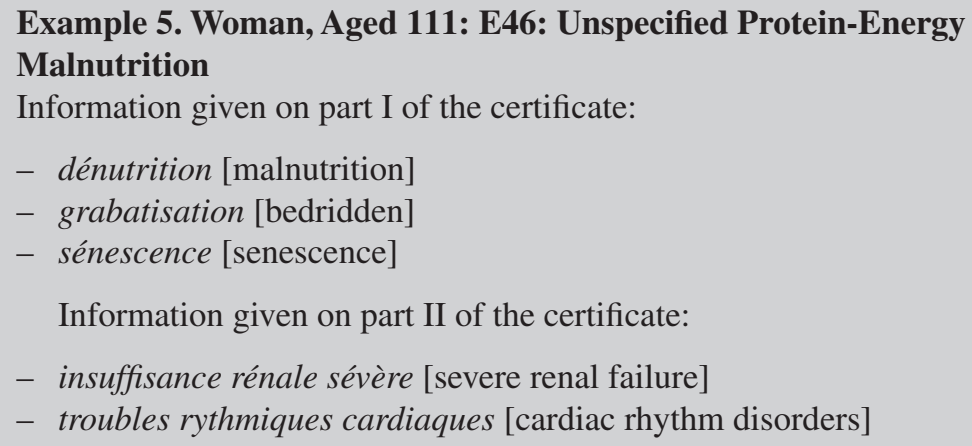

Similarly, in Example 6, which concerns the death of a man aged 110, the selection of "pulmonary oedema" (J81, ICD-10) as the cause of death seems overly precise. The information provided on both part I (pulmonary congestion and cachexia) and part II (old age) is quite vague. It appears that actual underlying cause of death was old age, rather than any specific respiratory disease.

\section{Example 6. Man, Aged 110: J81: Pulmonary Oedema}

Information given on part I of the certificate:

- encombrement pulmonaire [pulmonary congestion]

- cachexie [cachexia]

Information given on part II of the certificate:

- grand âge [old age] 


\title{
(D) Examples of "natural death"
}

In the last two Examples (7 and 8), "senility" was obviously the only possible choice, as no information was provided that would suggest another cause. This cause could be an appropriate choice for very old people who died without suffering from any precise lethal disease. While it is possible that the medical doctor did not pay enough attention to the case, it is also possible that some very old people died simply because they had reached an age at which it is common to die of "natural causes". In such cases, "senility" should be recognised as a non-ill-defined cause of death, at least among those who die at very old ages. The challenge lies in ensuring that this cause is not selected simply out of laziness.

\author{
Example 7. Woman, Aged 111: R54: Senility \\ Information on part I of the certificate: \\ - sénescence [senescence]; \\ - mort naturelle pendant sommeil [natural death while sleeping];
}

\section{Example 8. Man, Aged 112: R54: Senility}

Information on part I of the certificate:

- sénilité [senility]

- arrêt cardio-respiratoire [cardiorespiratory arrest]

All of the cases cited above are taken from our sample of 115 true supercentenarians. However, we systematically sorted all 160 cases in order to compare the causeof-death precision of the validated and the non-validated cases. This was done to give us an idea of the bias that could result from the analysis of the crude INSERM data that lack the IDL reference.

Among the 115 deaths of age-validated supercentenarians for the 2000-2014 period, 20 could be attributed to precise underlying causes of death, with no suspicion that a mistake in identifying the main cause had been made (Table 7.2). Another 25 deaths could be attributed to precise underlying causes of death, but with an accompanying deterioration in the individual's overall physical condition, which suggests that the initial cause was not necessarily the one selected in the coding process. An additional 32 cases could be explicitly attributed to a worsening of the individual's overall physical condition without a precise cause. And, finally, 38 deaths could be attributed to various causes related to old age, without necessarily referring to senility explicitly. At these very old ages, it is not surprising that the first category was the smallest, while the sizes of the less precise categories grew with the degree of inaccuracy (Fig. 7.7).

The distribution of the 45 cases for which the age was not validated was quite different (Table 7.3 and Fig. 7.7). There were more deaths in the first category; i.e., 


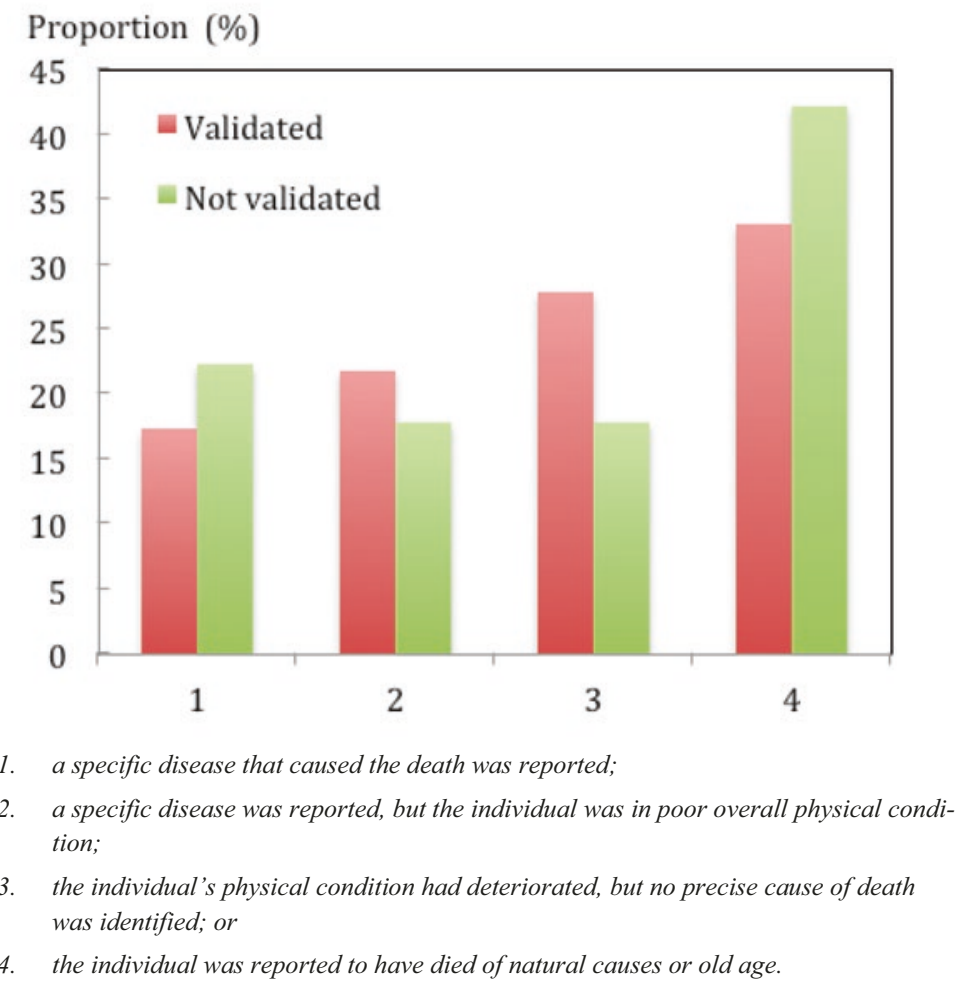

Fig. 7.7 Distribution into four degrees of cause-of-death precision of supercentenarian deaths, ages validated and non-validated (2000-2014)

in the most precise category. This was as expected because many of these nonvalidated deaths occurred at relatively young ages, when diagnosing the cause of death tends to be easier. There were also more deaths in the last category; i.e., the category that included unknown causes of death. This was likely because we had less information about these people, including about their causes of death. Consequently, fewer of the non-validated than the validated cases were assigned to categories 2 and 3.

Despite these important differences between the validated and the non-validated cases, the bias that would result from including all of the INSERM cases in our analysis would not be dramatic. Since the non-validated cases made up less than $30 \%$ of all cases, the distribution of all cases would differ little from that of the validated cases only (Table 7.2). 
Table 7.3 Summary of the types of causes of death at ages 110+

\begin{tabular}{l|c|c|c}
\hline \multirow{2}{*}{ Type of cause } & \multicolumn{3}{l}{ Number of deaths (proportion) } \\
\cline { 2 - 4 } & $\begin{array}{l}\text { Age } \\
\text { validated }\end{array}$ & $\begin{array}{l}\text { Not age } \\
\text { validated }\end{array}$ & Total \\
\hline 1. Precise cause of death & $20(17 \%)$ & $10(22 \%)$ & $30(19 \%)$ \\
\hline $\begin{array}{l}\text { 2. Specific disease with a worsening of the overall } \\
\text { physical condition }\end{array}$ & $25(22 \%)$ & $8(18 \%)$ & $33(21 \%)$ \\
\hline $\begin{array}{l}\text { 3. Worsening of the overall physical condition } \\
\text { without a precise cause }\end{array}$ & $32(28 \%)$ & $8(18 \%)$ & $40(25 \%)$ \\
\hline $\begin{array}{l}\text { 4. "Natural death", "age", unknown, etc. } \\
\text { Total }\end{array}$ & $38(33 \%)$ & $19(42 \%)$ & $57(36 \%)$ \\
\hline
\end{tabular}

\subsection{Conclusion}

Our analysis generated three main findings:

- Studying causes of death is worthwhile even among the oldest old. In a country like France, the cause-of-death pattern evolves regularly until around age 105. The share of deaths from circulatory diseases is quite stable over the age range, the share of deaths from cancers declines, and the share of deaths from respiratory/infectious diseases increases. The importance of ill-defined causes rises with age, partly due to a worsening of data quality. These insights open the door to an interesting discussion about the concept of cause of death at very old ages.

- Especially for deaths at very old ages, it is necessary to take into account multiple causes of death in assessing the quality of the medical information provided on the death certificate. It appears that the ICD rules for the selection of the underlying cause are not necessarily as convenient as for deaths at younger ages.

- While a minority of supercentenarian deaths can be attributed to a precise underlying cause, in most cases the death is attributed to an overall worsening of the person's physical condition, rather than to a precise underlying cause. This tends to be the case for two reasons:

- the precise cause of death that is identified is not decisive (it led to death only because of a general deterioration in health); or

- a general deterioration in health is the only cause that can be certified.

- It is possible that "senility" can be considered a real cause of death at very old ages. It becomes meaningful as an indicator because daily care may be more crucial to the survival of the oldest old than any conventional medical care or treatment (Fried et al. 2004; Motta et al. 2010). Supercentenarians tend to be so frail that any minor health event or brief lapse of attention on the part of their caregivers can be lethal. 


\section{References}

Berzlanovich, A. M., Keil, W., Waldhoer, T., Sim, E., Fasching, P., \& Fazeny-Dörner, B. (2005). Do centenarians die healthy? An autopsy study. The Journals of Gerontology Series A, Biological Sciences and Medical Sciences, 60(7), 862-865.

Cournil, A., Robine, J.-M., Maier, H., Gampe, J., \& Vaupel, J. W. (2010). The international database on longevity: Structure and contents. In H. Maier, J. Gampe, B. Jeune, J.-M. Robine, \& J. W. Vaupel (Eds.), Supercentenarians (pp. 31-40). Berlin: Springer Verlag.

Désesquelles, A., Demuru, E., Egidi, V., Frova, L., Meslé, F., Pappagallo, M., \& Salvatore, M. A. (2014a). Cause-specific mortality analysis: Is the underlying cause of death sufficient? Revue Quetelet, 2(1), 119-135.

Désesquelles, A., Demuru, E., Salvatore, M. A., Pappagallo, M., Frova, L., Meslé, F., \& Egidi, V. (2014b). Mortality from Alzheimer's disease, Parkinson's disease, and dementias in France and Italy: A comparison using the multiple cause-of-death approach. Journal of Aging and Health, 26(2), 283-315.

Evans, C. J., Ho, Y., Daveson, B. A., Hall, S., Higginson, I. J., \& Gao, W. (2014). Place and cause of death in centenarians: A population-based observational study in England, 2001 to 2010. PLoS Medicine, 11(6), e1001653.

Fried, L. P., Ferrucci, L., Darer, J., Williamson, J. D., \& Anderson, G. (2004). Untangling the concepts of disability, frailty, and comorbidity: Implications for improved targeting and care. Journal of Gerontology: Medical Sciences, 59(3), 255-263.

Horiuchi, S. (2006). Causes of death among oldest-old: Age-related changes in the cause-of-death distribution. In J.-M. Robine, E. M. Crimmins, S. Horiuchi, \& Z. Yi (Eds.), Human longevity, individual lifeduration, and the growth of the oldest-old population (pp. 191-214). Dordrecht: Springer.

Maier, H., Gampe, J., Jeune, B., Robine, J.-M., \& Vaupel, J. W. (Eds.). (2010). Supercentenarians (Demographic research monographs (A series of the Max Planck Institute for Demographic Research)). Berlin: Springer.

Mathers, C. D., Ma Fat, D., Mie, I., Chalapati, R., \& Lopez, A. D. (2005). Counting the dead and what they died from: an assessment of the global status of cause of death. Bulletin of the World Health Organization, (3), 83, 171-187.

Meslé, F. (2006). Causes of death among oldest-old: Validity and comparability. In J.-M. Robine, E. M. Crimmins, S. Horiuchi, \& Z. Yi (Eds.), Human longevity, individual lifeduration, and the growth of the oldest-old population (pp. 191-214). Dordrecht: Springer.

Meslé, F., Vallin, J., Robine, J.-M., Desplanques, G., \& Cournil, A. (2010). Supercentenarians in France. In H. Maier, J. Gampe, B. Jeune, J.-M. Robine, \& J. W. Vaupel (Eds.), Supercentenarians (pp. 119-136). Berlin: Springer.

Motta, M., Bennati, E., Vacante, M., Stanta, G., Cardillo, E., Malaguarnera, M., \& Giarelli, L. (2010). Autopsy reports in extreme longevity. Archives of Gerontology and Geriatrics, $50(1), 48-50$.

Nam, C. B., Hummer, R. A., \& Rogers, R. G. (1994). Underlying and multiple causes of death related to smoking. Population Research and Policy Review, 13(3), 305-325. 
Open Access This chapter is licensed under the terms of the Creative Commons Attribution 4.0 International License (http://creativecommons.org/licenses/by/4.0/), which permits use, sharing, adaptation, distribution and reproduction in any medium or format, as long as you give appropriate credit to the original author(s) and the source, provide a link to the Creative Commons license and indicate if changes were made.

The images or other third party material in this chapter are included in the chapter's Creative Commons license, unless indicated otherwise in a credit line to the material. If material is not included in the chapter's Creative Commons license and your intended use is not permitted by statutory regulation or exceeds the permitted use, you will need to obtain permission directly from the copyright holder. 